\title{
Medical Confidentiality And Human Immunodeficiency Virus (HIV) Infection: A Hypothetical Case
}

\author{
TM Gibson, WJ Coker
}

Air Cdr T M Gibson PhD MPhil MB ChB FFOM DAvMed DDAM FRAeS RAF(Retd)

Deputy Medical

Director

Corporate Health Ltd,

The Buckingham centre, Slough, SL1 4PG

E-mail: mikegibson@ corporate health.co.uk mikegibson@clara.co.uk

Air Cdr W J Coker OBE QHP BA(Hons)

$\mathrm{BSc}$ (Hons) MB ChB

LLB(Hons) FRCP

DAvMed FRAeS RAF

Deputy Director of Aviation Medicine (RAF)

Headquarters Personnel and Training

Command,

Royal Air Force

Innsworth,

Gloucester, GL3 1EZ

E-mail:

ddavmed@gtnet.gov.uk cokerwjan@aol.com

\begin{abstract}
This paper describes a hypothetical case of a HIV positive pilot. It explores legal and ethical aspects of medical confidentiality and discusses who, inside and outside military and medical circles, can be told of his condition in the light of the particular circumstances. Disclosure without the patient's consent is a serious step that should not be undertaken without advice from Service medico-legal departments and medical protection organisations.
\end{abstract}

\section{Introduction}

You are the Senior Medical Officer at a busy unit that is the home to two flying squadrons. As you come to the end of a busy sick parade, and start to look forward to an invigorating run at lunchtime, you are asked to see one of your pilots. You quickly review what you know about him. He is a well-liked and dashing officer, and an above average pilot, who is due to marry next week. His fiancée is the intelligence officer to one of the squadrons and is one of your patients. You are aware that she is deeply religious, somewhat prudish and has successfully defended her honour against determined efforts. She has consulted you prior to her forthcoming marriage and has told you that she has not had sexual intercourse.

The pilot comes in looking somewhat embarrassed. He quickly gets to the point. A bout of guilt led him to obtaining a private HIV test. This came back a week ago and was positive. As a result, he had a second, confirmatory test from the same private source. The result has just been made known to him and it is also positive. He asks for advice but implores you not to tell his fiancée as he is sure that she will call off the wedding. $\mathrm{He}$ declares that he would only practise "safe sex". He tells you he thinks that he acquired the infection from the stripper at his stag party 2 weeks ago. After briefing him on the time that it takes after exposure to become sero-positive, you press him for further information. Eventually he confesses that he has had a long-standing relationship with the wife of a pilot at a neighbouring base. He has had no other sexual exposures for the last 5 years and there are no other risk factors that you can identify.

Leaving aside any potential disciplinary and administrative issues arising from his inappropriate relationship, this paper will address the ethical and legal concerns relating to medical confidentiality and HIV status. It will then consider the specific question of whether or not you can tell the following people about the pilot's condition: his fiancée, the 2 squadron commanders concerned, your Consultant Adviser in Aviation Medicine, your Consultant Adviser in Genito-Urinary Medicine, the medically qualified head of your Service's Medical Branch, the stripper, the pilot and his wife at the neighbouring station and your medical officer colleague there.

\section{Ethical Considerations}

There is wide acceptance for the concept of an ethical duty of medical confidentiality. Kennedy and Grubb identify it as "[o]ne of the most fundamental ethical obligations owed by a doctor to his patient"(1). Beauchamp and Childress define confidentiality as:

"when one person discloses information to another.... and the person to whom the information is disclosed pledges not to divulge that information to a third party" (2).

Thus the information must be private, and voluntarily imparted under conditions of trust in a special relationship. If the patient subsequently consents to the information being divulged by the doctor then, although confidentiality is breached, there is no violation of the right to confidentiality. If consent is not given, then such a violation occurs. It may be argued that the modern trend of society towards freedom of information and transparency has enhanced individual requirements for medical confidentiality and also made it more difficult to achieve and protect.

Beaumont and Childress point out that patients necessarily surrender some of their privacy when they enter into a doctor-patient relationship (3). They identify three arguments to justify the existence of medical confidentiality. First, without confidentiality, patients would not trust their doctors with sufficient information to allow a therapeutic relationship. Second, the values of privacy and patient autonomy give weight to the requirement for the confidentiality that protects them. In other words, the patient has a right to privacy and a right to control 
the disposition of personal information (4). Third, the understanding that the doctor will not disclose private information about the patient provides a foundation for trust in the relationship. Thus, there is the expectation from the patient that the doctor will respect confidences, matched by an expectation from the doctor that the patient will confide private information to him. In the USA (and in private medicine), there is also an implied contractual promise of confidentiality (5).

The Hippocratic oath was arguably the first exposition of the ethical requirement for medical confidentiality. However, depending on the translation, the prohibition against breaching medical confidentiality may be couched in absolute, or more ambiguous, terms:

a. "All that may come to my knowledge in the exercise of my profession... which ought not to be spread abroad, I will keep secret and never reveal."(6)

b. "What I may see or hear in the course of the treatment, ...which on no account one must spread abroad, I will keep to myself holding such things shameful to be spoken about."(7)

The translation a. implies that there may in fact be items that may be spread abroad, whereas b. allows no such liberty. But can unauthorised disclosure be ethically justified in certain circumstances? In 1859, John Stuart Mill wrote:

“...the only purpose for which power can rightfully be exercised over any member of a civilised community, against his will, is to prevent harm to others"(8).

In some medical situations, particularly when moral judgements are to be made, the violation of confidence may be permissible. In other cases, where there is a statutory requirement, disclosure without consent may be mandatory. We listed these in an earlier paper (9). However, Beauchamp and Childress point out that:

“...difficult moral dilemmas cannot be resolved merely because a law requires disclosure and if a code of medical ethics were formulated only by reference to legal rules, that code would be inadequate"(10).

They propose a balancing exercise between the obligation of medical confidentiality on the one hand and probability of harm to others and the magnitude of that harm resulting from disclosure on the other. When there is a high probability of serious harm, the pressure to breach confidentiality increases. Thus absolute values of medical confidentiality cannot be justified where "outrageous circumstances of preventable injury and loss" (11) could result. However, some cases are clear-cut whilst others leave considerable room for uncertainty.

Modern thinking, therefore, does permit the more liberal interpretation of the Hippocratic oath. The General Medical Council (GMC) guidance (12) states that consent must be sought and given before disclosing information. However, information may be disclosed without the patient's consent in some circumstances. One of these situations is disclosure in the interests of others and one example given is when a patient may put others at risk. Further guidance is given in another GMC booklet on serious communicable diseases (13). This allows a doctor to disclose information about a patient in order to protect a person from serious harm. The booklet specifically deals with the subject of HIV and other communicable diseases:

“...you may disclose information to a known sexual contact of a patient with HIV where you have reason to think that the patient has not informed that person, and cannot be persuaded to do so."

\section{Legal Considerations}

The ethical reasons for confidentiality are discussed above, but these do not automatically have any legal status. One way of approaching this problem from a legal point of view is to ask whether a patient's remedy for a breach of confidence would arise contractually, in tort, or from equitable or fiduciary principles. In the United Kingdom, if the patient is a private patient, any claim for breach of confidentiality will lie in contract because there is a contractual relationship between the patient and his care provider. This contract will either contain an express term of confidentiality or such a term will be implied by the courts into the contract.

What of the National Health Service (NHS) patient? There is no contract in this situation, but could the patient claim through the tort of negligence? While negligence implies a degree of non-intentional conduct, it also includes deliberate actions undertaken on the basis of a false premise, of which the defendant should have been aware. This could include some breaches of confidentiality. However, a more useful approach under the law of tort is to suggest the existence of a tort of breach of confidence. Within this tort a doctor is under a legal obligation not to disclose confidential information concerning a patient obtained in the course of his professional practice. Before the requirements of this tort could be satisfied, three criteria must be fulfilled:

(a) The information must have the necessary quality of confidence about it. 
(b) The information must have been imparted in circumstances involving an obligation of confidence. This would include the patient's expectation that the information would remain confidential, or that the nature of the relationship between the giver and receiver of the information is such as to impose a presumption of confidentiality on the recipient of the information.

(c) Unauthorised use or disclosure of the information being to the detriment of the person giving it.

\section{Case Law}

While the law has been slow to develop a remedy for breach of confidence it clearly recognises such breaches as a proper basis for legal action. It is still not entirely clear how far a present action for breach of confidence will rest upon tort or upon a broad equitable principle (14). There are clear examples of the application of the law of confidence to situations involving privacy: Prince Albert $v$. Strange (15) concerning etchings by the Prince, Argyll v. Argyll (16) and Stephens v. Avery (17) concerning disclosure of sexual behaviour. The House of Lords decision in $A-G$ v. Guardian Newspapers (No 2) (18) clarified the basis for legal action and set out its requirements.

In $W$ v. Egdell (19), Scott J suggested that the legal basis for a claim of breach of medical confidentiality in this case should be framed in equity and that the principal remedy should be one of injunction. This case, which involved an appeal to a mental health review tribunal by a psychiatric patient detained in a secure hospital for an indefinite period, went to the Court of Appeal. It was held that Dr Egdell was justified in breaching patient confidentiality in this case because the public interest was in favour of disclosure. The obligation of confidentiality is a public and not a private interest. If a doctor breaches confidentiality, the law will ask: 'Is the balance of public interests in favour of breaching confidentiality or of maintaining it?' It should not be seen as a conflict between the public good and the private interest of the patient. It is in the public interest that patients should be able to trust their doctors to maintain confidentiality.

There have been several attempts to produce legislation on privacy, including the suggestion for a statutory tort of invasion of privacy. Privacy in this context is taken to include matters of health, personal communications and family and personal relationships. Usually to claim damages in a civil court for breach of confidentiality, a patient must be able to show that he or she has suffered harm. Such cases are rare and it is of course likely that bringing a case would give publicity to those very things the patient desired to keep secret in the first place. However, in Cornelius v Taranto (20) damages were awarded for injury to feelings caused by the breach of confidence. Furthermore, it is likely that a patient would be able to claim damages for improper disclosure about his health, even if he suffered no financial loss as a result. In $X v . Y(21)$ a health authority sought an injunction to prevent disclosure by a national newspaper of information about two doctors who were being treated for AIDS and employed by that authority. The defendant newspaper argued that disclosure was in the public interest and that the breach of confidence was therefore justified. It was held that such disclosure was not justified and that confidentiality of this information served a greater public good than its disclosure. This case did however illustrate that the legal obligation of confidence is not absolute and there are circumstances in which disclosure may be justified.

There is also the possibility of an action being brought in negligence by an aggrieved person who was not warned of danger, as a result of which harm ensued. Although not setting precedent in the UK, the most famous case is that of Tarassoff (22). In this case, a psychotherapist became aware of the intent of a spurned boyfriend to kill his exgirlfriend. She was not warned and her parents successfully sued after she was killed. Tobriner J stated that:

“...the public policy favoring protection of the confidential character of patient-psychotherapist communications must yield to the extent to which disclosure is essential to avert danger to others. The protective privilege ends where the public peril begins"(23).

Many jurisdictions have adapted the overall principle so that the danger has to be to an identifiable individual rather than to a non-specified target.

In addition to legal action at common law, the culpable and reckless transmission of the HIV virus may be held to be a criminal act. Recently, in Scotland an HIV positive man, who had not told his girlfriend of his HIV status, was sentenced to 5 years imprisonment for having unprotected sex with her, resulting in her sero-conversion (24). Similarly in England recently a HIV positive man was convicted of inflicting 'biological' grievous bodily harm, by insisting on unprotected sexual intercourse when he knew he was HIV positive (24a).

\section{Statute Law}

There are a number of different acts governing the disclosure of information. The Data Protection Act 1998 covers paper and computer records about patients and recognises individuals' rights to be told what information is being processed about them and under what circumstances this 
information can be disclosed. The Data Protection Act is the main piece of legislation in this area, although there are a number of other acts that affect patient confidentiality. These include the Human Fertilisation \& Embryology Act 1990, the Venereal Diseases Regulations 1974, the NHS and Primary Care Trusts (Sexually Transmitted Diseases) Directions 2000, the Abortion Regulations 1991, the Road Traffic Act 1988 and the Health Act 1999.

Certain diseases must be notified under the Public Health (Control of Disease) Act 1984 although AIDS is not one of them. The AIDS (Control) Act 1987 only requires Health authorities to provide anonymised information on patients with AIDS. Doctors treating a patient who dies must give the cause of death on a death certificate and this must not omit any condition that contributed to the death, however distressing this may be for the relatives.

Article 8 of the European Convention on Human Rights 1950 provides:

"Everyone has the right to respect for his private and family life, his home and his correspondence."

This was introduced into English law by the Human Rights Act 1998, which became law in October 2000. Since then, the Act has been used to uphold the right to privacy of movie stars (25) and a patient's medical confidentiality (26). At the same time the Act specifies a number of grounds permitting interference 'by a public authority' with this right. These grounds include national security, public safety, the economic well-being of the country, the prevention of disorder or crime, the protection of health or morals, or the protection of the rights and freedoms of others. It is clear that Article 8 does not give individuals an absolute right of privacy and that a public authority may consider it justified to override an individual's right to privacy in certain situations.

This qualified right to confidentiality under Article 8, echoes the caveat on freedom expressed by John Stuart Mill in 1859 and referred to above. While the right to privacy under the Human Rights Act is qualified, it does not depend on the existence of a special relationship between the giver and receiver of the information, as does the equitable approach to medical confidentiality.

\section{The Duty of Confidentiality on Doctors in the Armed Services}

All doctors in the Armed Services have the same duty of confidentiality to their patients as any other medical practitioner. However, they are also responsible to the Commanding Officer of a unit for the health and safety of the personnel in that unit. There may be occasions when the health of an individual may jeopardise the health or functioning of the unit as a whole, and in these circumstances the Commanding Officer may need to be given confidential information about an individual's health. This duty to the fighting unit may be seen as a particular example of the doctor's duty to society. Attempts will always be made to persuade an individual to give his consent for this information to be released, but if this is not forthcoming, the individual will be told that confidentiality will be breached. All servicemen, by enlisting, accept there will be more opportunities for disclosure than exist in civilian life, although such disclosure must always be justified. The General Medical Council's booklet "Confidentiality: Protecting and Providing Information" indicates that disclosure to employers can only be justified in "exceptional circumstances". Therefore, it is the lives or health of others that must be at demonstrable risk, and this must be clear before such information can be disclosed. On receipt of this confidential information the Commanding Officer will be informed that the information is confidential and that he should respect the nature of this information.

\section{Who and What Can You Tell?}

As a general rule in English law, disclosure remains the exception and not the rule. A physician or any other health professional, will not be held liable for harm done by a person in their care to a third person. The health professional will weigh his duty to the patient against the risk to others in society posed by the patient. To act in the public interest could excuse a breach of confidence, but the public interest does not impose a new duty on the health professional.

The GMC booklet on serious communicable diseases (HIV, hepatitis B and tuberculosis) indicates that a physician may disclose information concerning a patient to other health care professionals responsible for the care of the patient, or to the patient's sexual partner or spouse. This latter means specific identifiable individuals who are at risk of infection. In our scenario this could be taken to include specific individuals who may have been exposed to a risk of HIV infection by the patient and who could benefit from prophylactic treatment, given at the earliest possible opportunity. As a matter of guidance for medical practitioners it should be stated that while the GMC guidelines are not legally binding, the courts have rarely departed from these guidelines regarding matters of medical confidentiality and as in many other cases involving medical matters they tend to follow the lead given by the medical profession. Practitioners should study the GMC booklets on such issues and also seek advice from their defence societies if faced with these situations. You should also 
be aware that there is evidence that although notification of current sexual partners by HIV positive patients is satisfactory, that for previous partners is limited (27).

In the current, hypothetical scenario, the pilot has, on the one hand, very real reasons for wishing the information about his HIV status to be kept private. There would be the social embarrassment at the likely cancellation of his wedding, the potential loss of marital support, the disruption of his current flying tour and the loss of his livelihood as a pilot. On the other hand, it could be argued that there would be a public interest in such disclosure. Not only is he a risk to his sexual partners, but there is also the risk of subtle neurological and psychological changes that may pose a flight safety risk.

The Surgeon General's Policy Letter on HIV infection (28) merely states on confidentiality that:

"Medical Officers are responsible for the maintenance of medical confidentiality. It is necessary to obtain informed consent from the patient if a third party, who is not directly concerned in the patient's clinical care (even if the third party is medically or dentally qualified) is to be informed. Examples of third parties include CA GU Med (if not actually managing the patient), dentists and medical board doctors."

This must be qualified by the comment that there is no absolutely right or wrong answer. Often, the outcome depends on the circumstances. Whatever course of action is taken, it must be justifiable to the patient, to the GMC or even to a court of law. Note that HIV is not a notifiable disease in the UK. It is likely that in this rare circumstance, a unit doctor would discuss this issue with both a senior Service doctor and his medical defence organisation, but without divulging identities. The most important point to make is that you can obtain expert guidance from your Medico-Legal Department (29).

Bearing these points in mind, our suggestions concerning who can be told are given below. You may not agree with some, or any, of them. You might also like to consider your approach had the condition been syphilis, hepatitis B, or chlamydia.

\section{The Fiancée}

The fiancée is your patient as well as the pilot, and you also owe her a duty of care. Your immediate course of action should be to persuade Flt Lt $\mathrm{X}$ to tell his fiancée voluntarily. If he refuses, you should advise him that you will do so, citing the GMC guidance. It could be argued that she is not (yet) his sexual partner. However, it could be also argued that the prospect of a wedding in one week creates a reasonable expectation that she soon will be and is therefore at risk. The promise to practise only safe sex without telling her is of dubious efficacy. You should explain to the pilot that "safe sex" is essential to try to protect his partner but there is no absolute guarantee of protection. In addition, the promise of "safe sex" does not remove from you the ethical requirement to inform her of her fiancé's condition and to discuss with her the implications that this could have for their future together. It is also likely that she will want children at some stage of her marriage and she has a right to know that this desire could be rendered much more difficult by her husband's HIV status.

\section{The Squadron Commander}

The pilot will be medically downgraded under extant policy. All that the squadron commander, or the Commanding Officer in other circumstances, needs to know is that he is medically unfit and unlikely to regain a flying category. All pressure to be informed of the diagnosis should be courteously, but firmly, resisted.

\section{The Second Pilot's Squadron Commander}

First, you are not sure of the second pilot's HIV status. Neither is he your patient and the squadron commander is on another base. You have no requirement to notify him yourself directly (but see below).

\section{The Service Consultant Adviser (CA) in Aviation Medicine}

The CA may know the pilot concerned personally. Since he is almost certainly not in a therapeutic relationship with the patient, there is no requirement for him to know the diagnostic details. He should have access to the same information as the squadron commander. The same holds true for DDAvMed(RAF) or the CA in AvMed(RAF).

\section{The Service Consultant Adviser in Genito-Urinary Medicine (GUM)}

If the CA in GUM becomes involved in the therapeutic chain, then the pilot may be referred to him in the normal manner with appropriate disclosure of medical information, with the pilot's consent. As the GMC makes clear, it is important to give adequate information about the patient's condition to the professionals providing care (30). If the pilot were to refuse permission to reveal his status to health professionals providing care for him, you may disclose such information without consent if there was a serious risk of infection being transmitted to them and only after telling him that you were going to disclose. Otherwise, there is no requirement for the $\mathrm{CA}$ to possess anything other than anonymised data. 


\section{The Service Medical Director General}

The Director General will wish to be informed that a pilot is HIV positive, that the appropriate referrals have been made and actions taken. Apart from that, there is no requirement for him to know any details that would allow the patient to be identified. The Director General may wish to discuss the general issue of HIV positive aircrew with the respective consultant advisers and DDAvMed to ensure that appropriate policies are in place, but this could be achieved without reference to any particular individual.

\section{The Stripper}

Does the stripper really exist or is she a cover for the pilot's longstanding affair with the wife of a brother officer? Her existence should be either confirmed or denied by the pilot. You do not have a duty of care to the stripper. However, she is undeniably at risk. You should persuade the pilot to tell the stripper. If he refuses, then you will have to decide whether the exposure to risk by the third parties, and this applies to the stripper, the second pilot and his wife, outweighs your patient's privacy interest. If permission was not forthcoming, the advice of senior medical colleagues, your medico-legal department and the medical defence organisations should be sought before disclosure without the patient's permission. Such disclosure is a serious step and is detrimental to the principle that patients' confidences should be respected and maintained. If this is not done AIDS sufferers could be discouraged from seeking treatment. On the other hand an HIV patient who refuses to inform his partner of his HIV status is unlikely to succeed in an action against a health professional who breaches his duty of confidence and informs the partner. Disclosure to the stripper could be justified on the grounds that prophylactic treatment could reduce the chance of infection with HIV. The stripper, the second pilot and his wife may well be infected with HIV. Treatments are available to delay the course of the infection and all three should be made aware of their possible status as soon as possible to allow them to decide on the treatment options available to them. Given the circumstances of this case, both authors consider that disclosure would be justified. The most effective way of making arrangements to trace and warn all contacts may be through the HIV team attached to the local STD clinic.

\section{The Second Pilot}

The second pilot is not your patient and you owe him no direct duty of care. It would not be appropriate for the first pilot to tell him. However, he is presumably at risk and if he were to prove HIV positive he will have to be medically downgraded and grounded. The risk of a pilot developing AIDS after becoming HIV positive constitutes a flight safety hazard. As a military medical officer you owe a duty to your military superiors to maintain the efficiency of the fighting force and advise on any foreseeable flight safety hazard. In addition to these considerations, the arguments used to justify disclosure to the stripper will also apply in this case. The second pilot may have been infected by his wife or he may have been the primary source of the HIV infection. There may be risk factors in the second pilot's behaviour that also pose flight safety hazards and these will need to be explored. Such a disclosure in these circumstances will be most traumatic, both to the second pilot and to his wife, and will need to be handled sensitively. It may be that the best approach would be an indirect one, through his medical officer.

\section{The Wife of the Second Pilot}

The wife of the second pilot is not your patient and you do not owe her a duty of care. As, however, she is at risk of a serious illness, an appropriate course of action would be to persuade your patient, the first pilot, to inform her of this risk. If he were to refuse, the onus would be on you to follow the same course of action as for the stripper.

\section{The Second Pilot's Medical Officer}

An approach to your medical officer colleague at the station of the second pilot, on his behalf, will probably be morally, militarily and legally defensible. It would be convenient if his wife also happened to be this doctor's patient, but since this is a hypothetical case, she is not.

\section{Conclusion}

The spread of HIV has given rise to new problems in relation to confidentiality. AIDS is still highly resistant to therapy and often fatal. Its sexual connotation and its association with drug addiction lead to considerable stigmatization. This will be exacerbated in a military setting. In the above setting we have attempted to discuss the duties owed by military medical officers to their employer and to the sexual partners and future sexual partner of a patient who declines to pass on this information himself. HIV infection and AIDS are not notifiable conditions, and this helps to maintain confidentiality. Therefore, any departure from this anonymity requires both ethical and legal justification. In the above we have demonstrated how disclosure can be justified under certain circumstances.

\section{Acknowledgment}

We acknowledge the contribution of the Medical Law Department, University of 
Glasgow, for suggesting the original idea on which the scenario is based.

\section{References}

1. Kennedy I, Grubb A, Medical Law, 3rd ed, p1047, (London: Butterworths), 2000.

2. Beauchamp TL, Childress JF. Principles of Biomedical Ethics, 4th ed, p420, (Oxford: Oxford University Press), 1994.

3. Op. cit. at Page 418 .

4. Berry RM. "The genetic revolution and the physician's duty of confidentiality.” 7 Legal Med 1997; 18: 401-441.

5. Berry, loc. cit.

6. Mason JK, McCall Smith RA. Law and Medical Ethics, 5th ed, Appendix A. (London: Butterworths), 1999.

7. Edelstein L. "The Hippocratic Oath: text, translation and interpretation." In Burns C (ed), Legacies in Ethics and Medicine, p12, (New York: Science History Publications), 1977.

8. Mill JS. On Liberty. 1859. Cited by Kleinman I, Baylis B, Rodgers S, Singer P. Bioethics for clinicians: 8. Confidentiality. CMAJ 1997; 156: 521-4.

9. Gibson TM, Coker WJ. "Medical Confidentiality: the right of a Commanding Officer to know". $\mathscr{F} R$ Army Med Corps 2002; 148: 130-6.

10. Op. Cit., at 425 .

11. Berry, loc. cit. at 424

12. General Medical Council, Confidentiality: Protecting and Providing Information, (London: General Medical Council), 2000.

13. General Medical Council, Serious Communicable Diseases, para 22, (London: General Medical Council), 1997
14. Kitechnology B. V. v. Unicor $\mathrm{GmbH}$ Plastmaschinen [1995] FSR 765.

15. Prince Albert v. Strange (1849) 1 De G \& Sm 652.

16. Argyll v. Argyll [1967] Ch 302.

17. Stephens v. Avery [1988] Ch 449.

18. A-G v. Guardian Newspapers (No 2) [1990] 1 AC 109; [1988] 3 All ER 545.

19. Wv. Egdell [1990] 1 All ER 835

20. Cornelius v. deTaranto [2001] EMLR 329.

21. $X$ v. $Y$ [1988] 2 All ER 648.

22. Tarassof $v$. Regents of the University of California. 17 Cal 3d 425 (1976).

23. Tarassof $v$. Regents of the University of California (Tarassof II), 551 P2d 334 (1976) at 347.

24. $R v$ Kelly (unreported). Discussed in Bird SM, Leigh Brown AJ. Criminalisation of HIV transmission: implications for public health in Scotland. BMJ 2001; 323: 1174-7.

24a.R v. Dica. The Times 15 Oct 03.

25. Douglas and Zeta-Jones and Others v. Hello! [2002] 3 WLR 542.

26. Campbell v. Mirror Group Newspapers [2002] EWCA Civ 1373.

27. Mir N, Scoular A, Lee K, Taylor A, Bird SM, Hutchinson S, Worm A-M, Goldberg D. "Partner notification in HIV-1 infection: a population based evaluation of process and outcomes in Scotland." Sex Trans Inf 2001; 77: 187-9.

28. Surgeon General's Policy Letter b 04/02, D/SG(Med Pol)/370/1/4 dated 26 Mar 02.

29. Contact details are: RN 02392768064 (or 9380 68064); Army 01276412727 (or 94261 2727); RAF 01452712612 ext 5854 (or 954715854 ).

30. General Medical Council, Serious Communicable Diseases, para 18, (London: General Medical Council), 1997. 